\title{
Development of an electrochemical DNA biosensor for detection of specific Mycobacterium tuberculosis sequence based on poly(L-glutamic acid) modified electrode
}

\author{
MERVE YESIL ${ }^{\mathrm{a}}$, SONER DONMEZ $^{\mathrm{b}, *(D)}$ and FATMA ARSLAN ${ }^{\mathrm{a}}$ \\ ${ }^{a}$ Department of Chemistry, Faculty of Science, Gazi University, 06500, Ankara, Turkey \\ ${ }^{b}$ Bucak School of Health, Mehmet Akif Ersoy University, 15300, Bucak, Burdur, Turkey \\ e-mail: merve.ysil@gmail.com; sdonmez@mehmetakif.edu.tr; fatma@gazi.edu.tr
}

MS received 19 April 2016; revised 4 August 2016; accepted 9 August 2016

\begin{abstract}
An electrochemical DNA biosensor was developed by avidin-biotin interaction of a biotinylated probe and avidin-attached, poly(L-glutamic) acid coated pencil graphite electrode (PGA/PGE) for detection of specific Mycobacterium tuberculosis DNA sequence. The discrimination of fully complementary hybridization and mismatch hybridization was carried out by electrochemical reduction current of Meldola's Blue (MDB) in square wave voltammetry (SWV). The calibration graph of the DNA biosensor was linear between 1.5-12.5 nM and the detection limit was calculated as $1.3 \mathrm{nM}$. The proposed biosensor successfully discriminated short and long oligonucleotides related to DNA sequence of Mycobacterium tuberculosis in optimal condition.
\end{abstract}

Keywords. Poly(L-glutamic acid); DNA sensor; Mycobacteriumtuberculosis.

\section{Introduction}

Tuberculosis (TB) is a major health problem caused by Mycobacterium tuberculosis (MTb). TB infects approximately 54 million people worldwide. Each year, about 8 million new cases are discovered resulting in about 2.4 million of deaths. ${ }^{1,2}$ Southern hybridization techniques, radiographic methods, restriction fragment length polymorphism, bacteriological culture, immunoassays and polymerase chain reaction are some of the conventional methods for TB diagnosis. However, they are time consuming, labor intensive and expensive. ${ }^{3}$

DNA biosensor can provide alternative solution for pathogen diagnosis due to their rapid response, low cost, ease of operation and sensitivity. Biosensor surface for immobilization of biomolecule is very significant to develop sensitive and selective biosensor. ${ }^{3,4}$ In this context, the modification of polymeric species by coating on to the electrode surfaces (especially using electro-polymerization technique) gives wide flexibility because they contain functional groups which can provide excellent high surface coverage using thick multilayer coating. ${ }^{5}$

Recently, various synthetic amino acids have attracted much interest from biosensor researchers due to some benefits such as their biocompatibility, reproducibility, good stability and rapid preparation. ${ }^{5-10}$ There are a few

*For correspondence reports about usages of polymerized amino acids for fabrication of DNA biosensor. Among these amino acids, glutamic acid can be directly electropolymerized onto electrode from monomers and it is highly useful for immobilization of nucleic acid due to the free carboxyl group. ${ }^{7}$

Immobilization of biomolecules by using avidin-biotin based procedure is very attractive today owing to its simplicity and excellent robustness. This immobilization method has some advantages, such as very low quantity of biotinlayted ligand which is sufficient for immobilization. There are various commercially available biotinylated reagents, almost unlimited number of immobilization can occur in a single biotinylation reaction and their surfaces have lower electrostatic charges. ${ }^{11}$

In present work, a novel electrochemical DNA biosensor was developed by using poly(L-glutamic acid) (PGA) coated onto pencil graphite electrodes in order to detect specific DNA sequences of MTb. Avidin biotin interaction was used for the immobilization method. In this report, avidin was attached to poly(L-glutamic acid)-modified electrode by covalent attachment and its application in DNA biosensor was performed for the first time. The DNA hybridization reaction was recorded by square wave voltammetry (SWV) measurement of the intercalated Meldola's Blue (MDB). After fabrication of DNA biosensor, optimum working conditions 
were determined. The application of biosensor was carried out in optimal conditions by using synthetic PCR analogue of MTb sequences.

\section{Experimental}

\subsection{Apparatus and chemicals}

Voltammetric measurements were carried out by a CHI 1020 electrochemical analyzer with a three-electrode cell. Working, auxiliary and reference electrodes were pencil graphite (PGE) (surface area of $0.095 \mathrm{~cm}^{2}$ ), platinum wire and $\mathrm{Ag} / \mathrm{AgCl}(3 \mathrm{M} \mathrm{KCl})$, respectively. The pencil graphite was obtained as pencil 'lead' from a local bookstore, which is Tombow of type HB. A digital $\mathrm{pH}$ meter (Orion Model 720A) was used for measuring the $\mathrm{pH}$ values of the prepared buffer solutions. Grant W14 thermostat was employed for temperature control of solution.

$\mathrm{N}$-(3-Dimethylaminopropyl)-N'-ethylcarbodiimide (EDC), N-hydroxysulphosuccinimide (NHS), L-Glutamic acid and avidin were purchased from Sigma. All other chemicals were analytical reagent grade. All solutions were prepared by using Ultrapure water $\left(18 \mathrm{M} \Omega \mathrm{cm}^{-1}\right)$.

In this study, a DNA probe was designed for M. tuberculosis $(\mathrm{H} 37 \mathrm{Rv})$ genome. All oligonucleotides were provided by Ella Biotech (Germany) as lyophilized powder. The oligonucleotide sequences are in Table 1.

The stock solutions of the oligonucleotides $(500 \mu \mathrm{g} /$ $\mathrm{mL}$ ) were prepared with ultra-pure distilled water and kept frozen. More diluted solutions of probes and targets were prepared using $0.50 \mathrm{M}$ acetate buffer $(\mathrm{pH} 4.80)$ solution containing $20 \mathrm{mM} \mathrm{NaCl}$ and $2 \times \mathrm{SSC}$ (Saline Sodium Citrate) buffer solution ( $\mathrm{pH} 7.0$ ), respectively. A fresh PGE surface was used for each measurement. Experiments were performed at room temperature in an electrochemical cell.

\subsection{Preparation of poly(L-glutamic acid) modified electrodes}

Electrical contact of the pencil graphite was provided by means of a copper drill chuck. The pencil graphite was placed vertically and immersed in the solution as working electrode. The length of electrode was $50 \mathrm{~mm}$ and diameter, $0.3 \mathrm{~mm}$. A total of $5 \mathrm{~mm}$ of pencil graphite was immersed in solution during each measurement.

A poly(L-glutamic acid)-modified electrode was fabricated by cyclic voltammetry in aqueous solution containing $0.02 \mathrm{M}$ L-glutamic acid in $0.1 \mathrm{M}$ phosphate buffer solution (PBS) of $\mathrm{pH}$ 8.0. Electropolymerization of L-glutamic acid was performed by applying potential between -0.8 and $+2.0 \mathrm{~V}$ at a scan rate of $100 \mathrm{mV} / \mathrm{s}$ for 30 cycles using cyclic voltammetry. The electrode was thoroughly rinsed with deionized water to remove the unreacted glutamic acid monomer after electropolymerization. ${ }^{7}$

The terminal carboxylic acid groups of PGA-modified PGE (COOH-PGE) was activated by immersion in an aqueous solution containing $8 \mathrm{mM}$ NHS and $5 \mathrm{mM}$ EDC for $1 \mathrm{~h}$ at room temperature. After the electrode was washed with $0.1 \mathrm{M}$ PBS, it was functionalized with avidin in PBS containing $1000 \mu \mathrm{g} / \mathrm{mL}$ avidin for $2 \mathrm{~h}$ at room temperature, and rinsed again with $0.1 \mathrm{M}$ PBS afterwards.

\subsection{Immobilization of the biotinylated DNA probe onto the PGA/PGE and its hybridization with target DNA}

The avidin-modified PGA/PGE was immersed in $0.1 \mathrm{M}$ PBS ( $\mathrm{pH}$ 8.0) containing $10 \mathrm{nM}$ biotinylated probe DNA in order to immobilize the biotinylated probe DNA for $30 \mathrm{~min}$ at room temperature. Afterwards, it was rinsed with $1 \times \mathrm{SSC}$ buffer for $5 \mathrm{~min}$ to remove the unbound DNA probe.

Table 1. Oligonucleotidesequences employed.

\begin{tabular}{lcc}
\hline Oligonucleotide name & Length & Sequence \\
\hline Probe DNA (pMTb) & 25 & $5^{\prime}$-biotin GACCAAATAGGTATCGGCGTGTTCA-3' \\
Complementary Target DNA (cMTb) & 25 & $5^{\prime}$-TGAACACGCCGATACCTATTTGGTC-3' \\
Non-complementary target DNA-1 (ncMTb-1) & 20 & $5^{\prime}$-TAATGAGGGCTGCGGGTGGG-3' \\
Non-complementary target DNA-2 (ncMTb-2) & 17 & $5^{\prime}$-GTGGGTGATATGTGTGG-3' \\
Non-complementary target DNA-3 (ncMTb-3) & 20 & $5^{\prime}$-CAATGAGGGCGGCGGGTGGA-3' \\
Synthetic complementary Tb & 50 & $5^{\prime}$-TCTCGGGGTTTGGGTCTGACGACTT \\
PCR analogue (RS-cMTb) & & GAACACGCCGATACCTATTTGGTC-3' \\
Synthetic Non-complementary & 50 & $5^{\prime}$-TAATGAGGGCTGCGGGTGGGCGGGAT \\
PCR analogue-1 (RS-ncMTb-1) & & GGCTCCTGTCCCCCCGTGGCTCTC-3' $^{\prime}$ \\
Synthetic Non-complementary & 50 & $5^{\prime}$-GTGGGTGATATGTGTGGGGCCGTCTTC \\
PCR analogue-2 (RS-ncMTb-2) & & CTCGTGGGACAAGCCTTCACGTT-3' \\
\hline
\end{tabular}


The probe-immobilized DNA biosensor was immersed into $2 \times$ SSC hybridization buffer containing $1.0 \mu \mathrm{M}$ target DNA (complementary or non-complementary) for $30 \mathrm{~min}$ at room temperature. The DNA biosensor was then rinsed with $2 \times \mathrm{SSC}+0.1 \%$ SDS buffer for $5 \mathrm{~min}$ to remove the unbound oligonucleotides.

\subsection{Interaction with the intercalator molecule and transduction of Meldola's blue by SWV}

Following hybridization, the DNA biosensors were immersed for $5 \mathrm{~min}$ in $20 \mathrm{mM}$ tris buffer solution (TBS) (pH 7.0) containing $20 \mathrm{mM} \mathrm{MDB} .{ }^{12,13}$ Then, the biosensors were immersed in washing buffer $(1 \times \mathrm{SSC}+$ $0.1 \%$ SDS, $\mathrm{pH} 7.0$ ) for $5 \mathrm{~min}$. The DNA sensor was then dipped into the TBS ( $\mathrm{pH}$ 7.0) for voltammetric measurement. The change in the reduction signal of MDB was measured by using SWV scanning from $+0.4 \mathrm{~V}$ to $-0.5 \mathrm{~V}$. Experimental conditions: frequency of $15 \mathrm{~Hz}$, step potential of $0.01 \mathrm{~V}$ and amplitude of $0.025 \mathrm{~V}$. The electrochemical detection protocol is illustrated in Figure 1.

\subsection{Stability studies}

The biosensors were immersed in buffer solution $(1 \times \mathrm{SSC}$ containing $2.5 \%(\mathrm{w} / \mathrm{v})$ of glucose) for $5 \mathrm{~min}$ and stored in a refrigerator at $+4^{\circ} \mathrm{C}$ in order to determine the long-term dry storage. ${ }^{7}$ Voltammetric transductions were performed after $0,1,2,3,4,5,10,15,30$ and 60 days. Before each voltammetric transduction, the biosensor was washed with deionized water and incubated in $1 \times \mathrm{SSC}$ for $30 \mathrm{~min}$. Results were expressed as percentage of signal decreases compared to freshly prepared biosensor response.

\section{Results and discussion}

In the present work, electrochemical detection of DNA hybridization was carried out by using changes in reduction signal of MDB. MDB shows a low reduction signal when interacting with single strand DNA since this kind of DNA does not have duplex form. However, the reduction signal of MDB increases following the hybridization because MDB can selectively bind to duplex form of DNA. ${ }^{13}$ In addition, when using PGA coated electrode, biosensor has shown superior electrocatalytic activity on MDB reduction signal (Figure 2).

\subsection{Electropolymerization of L-glutamic acid onto PGE}

As shown in Figure 3, poly(L-glutamic acid) film was fabricated onto PGE by using cyclic voltammetry

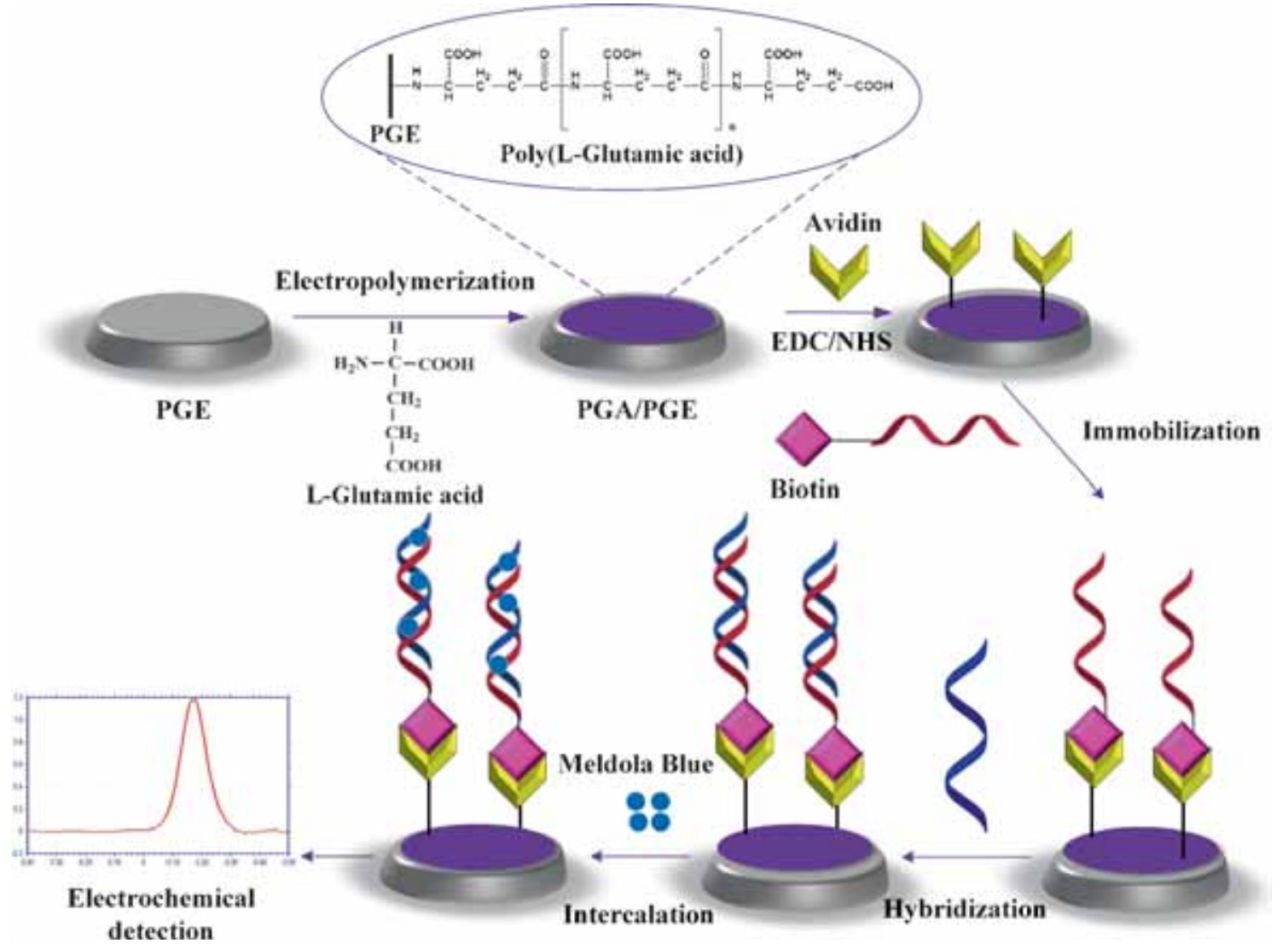

Figure 1. Schematic illustration of experimental procedure for the DNA sensor. 


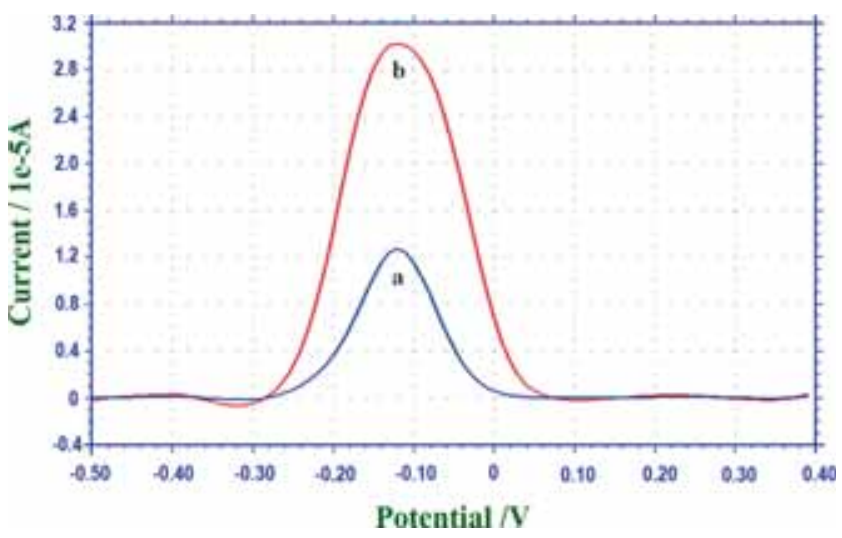

Figure 2. Square wave voltammograms of $20 \mathrm{mM}$ MDB reduction in TBS: a) PGE and b) PGA-coated PGE.

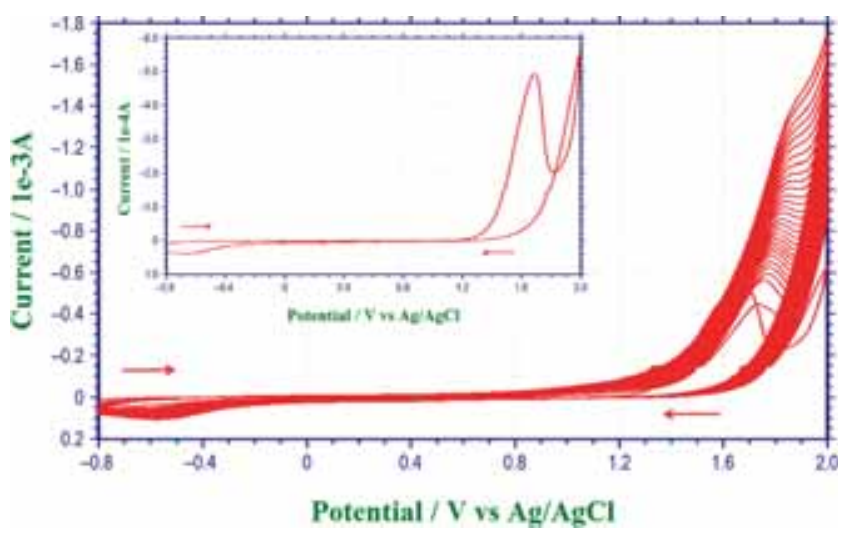

Figure 3. $\mathrm{CV}$ of the Poly-L-Glutamic acid film growth on PGE surface (scan rate of $100 \mathrm{mV} / \mathrm{s}$ for 30 cycles in $0.1 \mathrm{M}$ PBS (pH 7.0) containing 0.05 M glutamic acid).

technique. An oxidation peak obtained at about $+1.68 \mathrm{~V}$ which can be related to a peak of free radical (the inset of Figure 3) in the first scan. At the second scan, the peak at $+1.68 \mathrm{~V}$ disappeared whereas a new wide peak appeared at about $+1.75 \mathrm{~V}$. Increase of the new peak with the number of cycles shows that L-glutamic acid could deposit onto PGE surface by electropolymerization. ${ }^{14}$ Afterwards, the electrode was rinsed with distilled water to remove physically adsorbed material and allowed to dry in ambient air. Then, a gray color on PGE showed that a polymer film was formed onto PGE. The reaction mechanism can be explained as follows: L-glutamic acid was oxidized to free radicals at the surface of PGE and the free radicals then combined with the surface of PGE rapidly, resulting in the possible structure of electropolymerized poly(L-glutamic acid) ${ }^{5}$

\subsection{Optimization of working conditions}

Electrochemical DNA sensors can be greatly affected by the following experimental conditions: probe concentration, hybridization time, immobilization time and

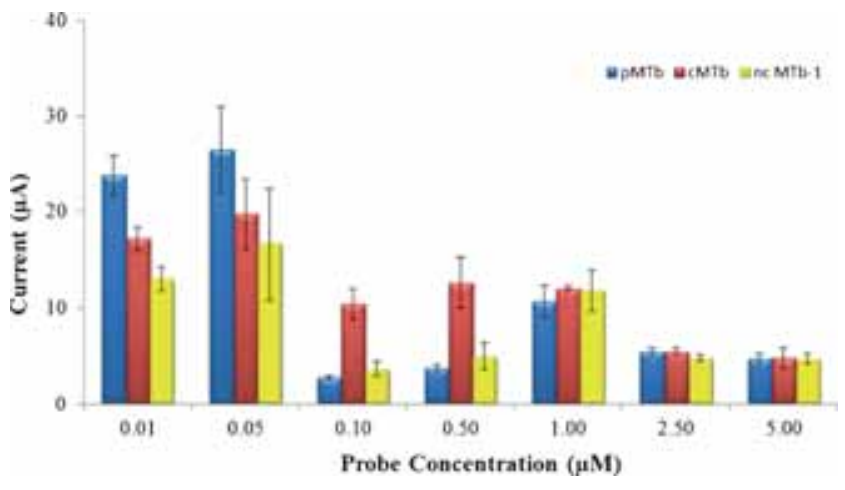

Figure 4. Histogram for the dependence of the reduction signal of MDB by increasing concentration of probe (pMTb). Experimental conditions were as follows: probe immobilization time $30 \mathrm{~min}$ in $\mathrm{PBS}$; hybridization time, $30 \mathrm{~min}$ with $1 \mu \mathrm{M}$ cMTb and nc MTb- 1 in $2 \times$ SSC; MDB binding time, $5 \mathrm{~min}$ in TBS containing $20 \mathrm{mM} \mathrm{MDB}$; voltammetric technique was $\mathrm{SWV}$ (frequency $=25 \mathrm{~Hz}$, step potential $=0.01 \mathrm{~V}$, amplitude $=0.025 \mathrm{~V})$.

temperature. ${ }^{7,15,16}$ The sensitivity and selectivity of the DNA biosensor was related to the surface coverage of probes on the electrode. ${ }^{17}$ In order to obtain the best probe density on electrode, we used a series of probe concentration ranging from $0.01 \mu \mathrm{M}$ to $5.0 \mu \mathrm{M}$ by keeping concentration of complementary and non-complementary oligonucleotides constant. As shown in Figure 4, the highest discrimination ratio between fully complementary and non-complementary oligonucleotide $(\mathrm{c} / \mathrm{nc})$ was obtained at a probe concentration of $0.5 \mu \mathrm{M}$. In addition, almost same signal was obtained from probe and non-complementary oligonucleotides which indicates MDB does not accumulate non-complementary hybrid. Thus, $0.5 \mu \mathrm{M}$ was chosen as the optimal probe concentration for further experiments.

It was reported in the literature, immobilization and hybridization time between target and probe sequences affects the detection of target DNA. ${ }^{12,16}$ The immobilization time varying from 5 to 90 min was tested to find optimal immobilization time (probe concentration $0.5 \mu \mathrm{M}$ and target concentration $0.1 \mu \mathrm{M}$ ). The best discrimination of MDB signal between complementary and non-complementary was observed that immobilization time of $30 \mathrm{~min}$ (Figure 5a) was optimal.

In order to find optimum hybridization time, the duration of hybridization was changed from $5 \mathrm{~min}$ to $60 \mathrm{~min}$ (Figure 5b). 30 min was selected as optimum hybridization time due to best discrimination between complementary and non-complementary oligonucleotides.

The effect of hybridization temperature was determined as follows: the biosensor was immersed for $30 \mathrm{~min}$ in $2 \times \mathrm{SSC}$ buffer ( $\mathrm{pH} 7.0$ ) containing $0.1 \mu \mathrm{M}$ complementary oligonucleotide at different temperatures 


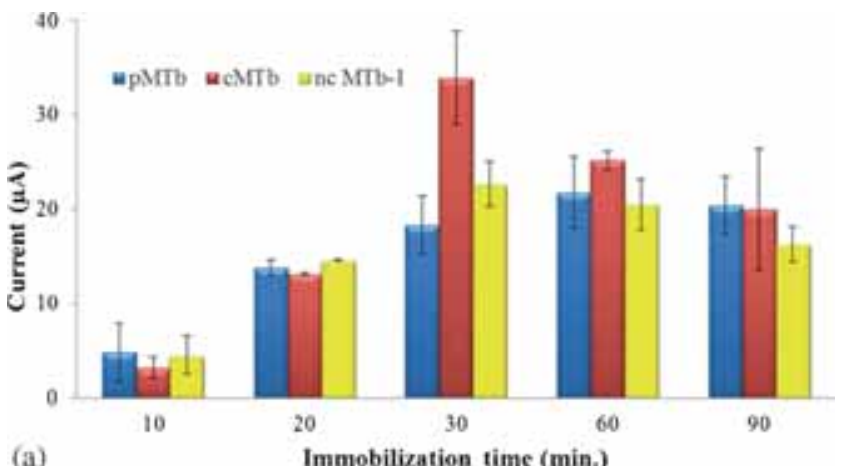

(a)

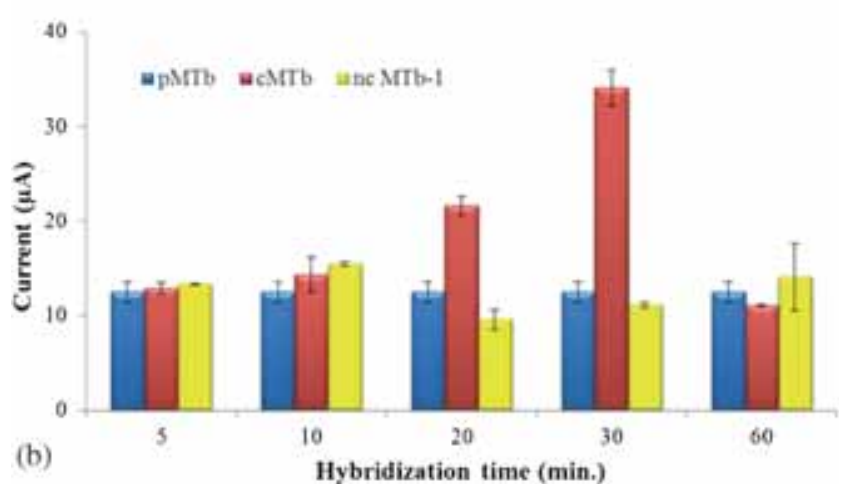

Figure 5. Dependence of probe immobilization time (a) and hybridization time (b) on the reduction signal of MDB. Experimental conditions were as follows: probe immobilization time $30 \mathrm{~min}$ in PBS with $0.5 \mu \mathrm{M}$ pMTb; hybridization time, 30 min with $0.1 \mu \mathrm{M}$ cMTb and nc MTb- 1 in $2 \times \mathrm{SSC}$; MDB binding time, $5 \mathrm{~min}$ in TBS containing $20 \mathrm{mM} \mathrm{MDB}$; voltammetric technique was SWV (frequency $=25 \mathrm{~Hz}$, step potential $=0.01 \mathrm{~V}$, amplitude $=0.025 \mathrm{~V})$.

varying from 25 to $70^{\circ} \mathrm{C}$ and $\mathrm{MDB}$ reduction signals were monitored. The maximum MDB signal was obtained at $60^{\circ} \mathrm{C}$ (Figure 6) and hence, it was determined as the optimum hybridization temperature. Above $60^{\circ} \mathrm{C}$, MDB signal was decreased because high temperature could cause DNA denaturation. ${ }^{18}$ Although $60^{\circ} \mathrm{C}$ was optimum hybridization temperature, room temperature $\left(25^{\circ} \mathrm{C}\right)$ was preferred as working temperature since MDB signal was enough for further biosensor studies.

\subsection{Selectivity of the biosensor}

Selectivity of the DNA biosensor was determined by using three different target oligonucleotides of which one of them was fully complementary oligonucleotide and the others were non-complementary oligonucleotides. In addition, the DNA biosensor was tested with synthetic PCR analogues (50 bases) of MTb which were RS-cMTb, RS-ncMTb-1 and RS-ncMTb-2.

The reduction peak current of MDB on the probeimmobilized electrode was $12.19 \pm 0.71 \mu \mathrm{A}$. After hybridization with ncMTb-1, ncMTb-2 and ncMTb-3

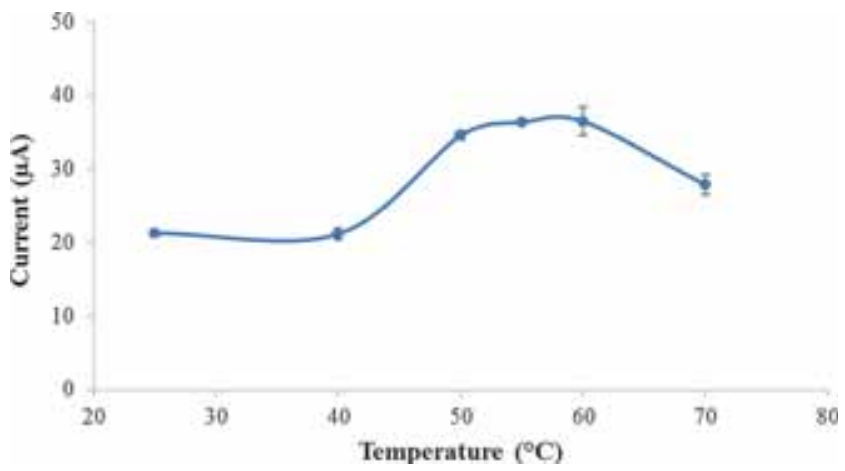

Figure 6. The effect of temperature on the response of the biosensor. Experimental conditions were as follows: probe concentration $0.5 \mu \mathrm{M}$; immobilization and hybridization time $30 \mathrm{~min}$; target concentration $0.1 \mu \mathrm{M} \mathrm{cMTb}$ and $\mathrm{nc}$ MTb- 1 in $2 \times$ SSC; MDB binding time, 5 min in TBS containing $20 \mathrm{mM} \mathrm{MDB}$; voltammetric technique was SWV (frequency $=25 \mathrm{~Hz}$, step potential $=0.01 \mathrm{~V}$, amplitude $=$ $0.025 \mathrm{~V})$.
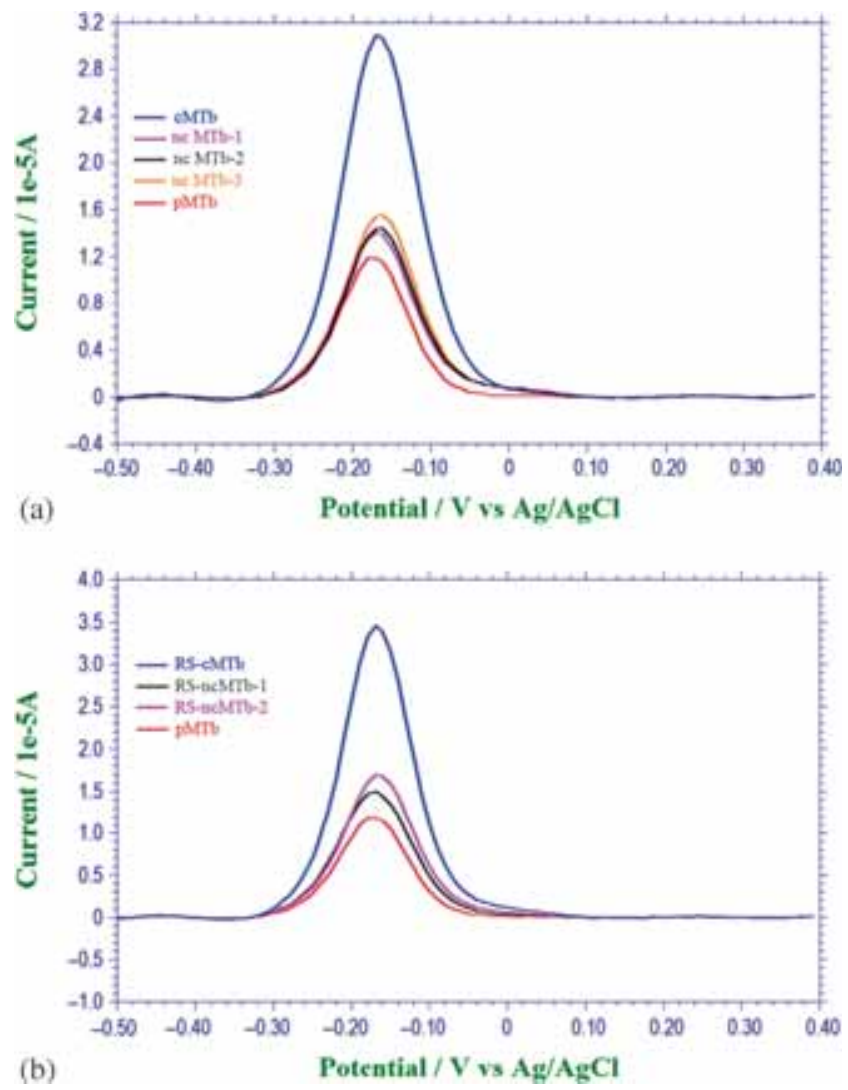

Figure 7. SWV of reduction signal of MDB on, (a) probeimmobilized PGA/PGE (pMTb), complementary DNA (cMTb), non-complementary DNAs (nc MTb-1, nc MTb-2, nc MTb-3); (b) pMTb, Complementary DNA (RS-cMTb) and non-complementary DNAs (RS-ncMTb-1 and RS-ncMTb-2) synthetic single-stranded PCR product analogues.

sequences, it was $13.70 \pm 0.34 \mu \mathrm{A}, 13.77 \pm 0.89 \mu \mathrm{A}$ and $14.27 \pm 0.80 \mu \mathrm{A}$, respectively (Figure 7a). The signal of MDB was nearly same with probe and non-complementary sequences (nMTb-1, ncMTb-2 and ncMTb-3). 
This proved that there was no hybrid form between noncomplementary sequences and probe for intercalation of MDB. On the other hand, after hybridization with $\mathrm{cMTb}$, the biosensor response increased almost two fold compared to non-complementary sequences (29.86 $\pm 0.29 \mu \mathrm{A}$ ) because duplex form allowed intercalation of MDB (Figure 7a).

The DNA biosensor was also tested against synthetic PCR analogues corresponding to $\mathrm{M}$. tuberculosis genome and mismatch sequences. It successfully separated synthetic PCR analogues which corresponded to RS-cMTb, RS-ncMTb1 and RS-ncMTb2 (Figure 7b). The currents of MDB for these sequences were 32.72 $\pm 0.45 \mu \mathrm{A}, 15.05 \pm 1.21 \mu \mathrm{A}$ and $16.06 \pm 0.52 \mu \mathrm{A}$, respectively. Since RS-cMTb was perfectly matched for probe, its signal was higher than those of RS-ncTb1 and RS-ncTb2.

\subsection{Stability of the DNA biosensor}

Dry storage stability was tested within 2 months (Figure 8). Although the current response of the biosensor decreased about $20 \%$ from its initial response after 1 day, it maintained about $65 \%$ of its initial response after 2 months of storage. This result indicated that the DNA biosensor can be used for long term application.

\subsection{Diagnostic performance of the biosensor}

The sensitivity of the biosensor was investigated using probe immobilized electrode to hybridize with different concentrations of the target cMTb oligonucleotide. As shown in Figure 9, the SWV peaks of MDB are strongly dependent on the concentration of cMTb. The more hybridization of target DNA with probe DNA, larger is the amount of hybrid DNA formed on the electrode. Therefore, more MDB intercalated with double strand DNA and the bigger response of MDB reduction signal was observed. As the concentration of $\mathrm{cMTb}$ sequence was increased from $1.5 \mathrm{nM}$ to $75 \mathrm{nM}$, SWV peak of MDB increased and leveled off at $50 \mathrm{nM}$. There is a linear relationship between SWV peak of MDB and $\mathrm{cMTb}$ concentration from $1.5 \mathrm{nM}$ to $12.5 \mathrm{nM}$ with a correlation coefficient of 0.9931 (inset of Figure 9). The regression equation was $\mathrm{I}(\mu \mathrm{A})=8.84+1.07 \mathrm{c}(\mu \mathrm{M})$, where $\mathrm{I}$ is current and $\mathrm{c}$ is concentration. The detection limit was calculated as $1.3 \mathrm{nM}$ (by using equation, LOD $=3.3 \times\left(\mathrm{S}_{\mathrm{y}} / \mathrm{S}\right)$ where $\mathrm{S}_{\mathrm{y}}$ is the standard deviation of the response of the curve and $\mathrm{S}$ is the slope of the calibration curve), which was lower than some previous

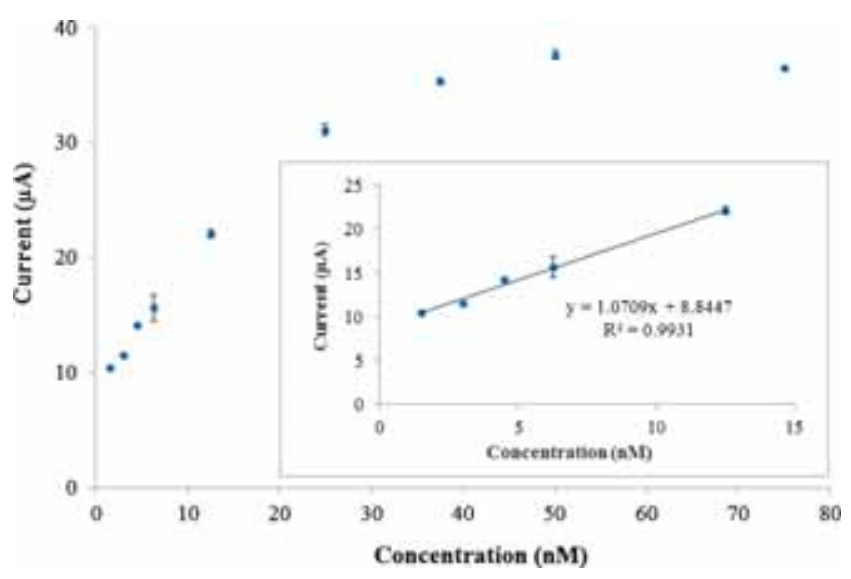

Figure 9. Plot of the peak current $v s$. the concentration of $\mathrm{cMTb}$ from $1.5 \mathrm{nM}$ to $75 \mathrm{nM}$. Inset: calibration graph for concentration range $1.5 \mathrm{nM}$ to $12.5 \mathrm{nM}$.

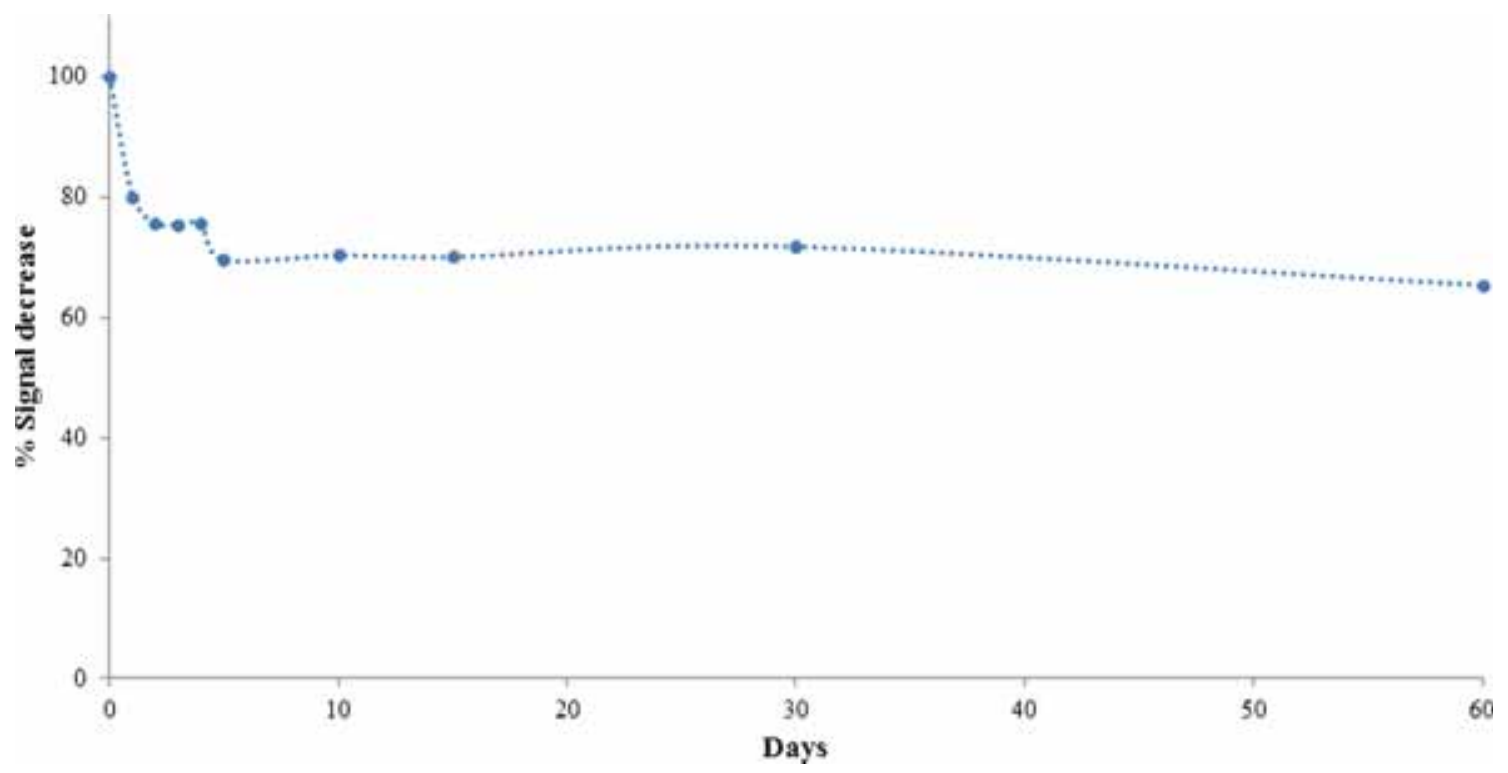

Figure 8. Dry storage stability of the DNA biosensor. 
reported values. ${ }^{19,20}$ The relative standard deviation was calculated as $1.46 \%$ using three different detections (target concentration $0.1 \mu \mathrm{M}$ ) indicating the good reproducibility of this proposed biosensor.

\section{Conclusions}

In this work, a novel electrochemical DNA biosensor was fabricated by electropolymerization of L-glutamic acid onto disposable pencil graphite electrode for detection of M. tuberculosis DNA sequence. Avidin-biotin interaction was used for immobilization method. The presence of poly-L-glutamic acid (PGA) onto biosensor surface provides suitable platform for immobilization of probe DNA because of free carboxyl groups. In addition, PGA-modified biosensor showed excellent electrocatalytic effect on the reduction of Meldola's Blue (MDB). The developed biosensor exhibited high sensitivity, selectivity, wide dynamic detection range and long-term stability. It effectively discriminated complementary (cMTb) and non-complementary (ncMTb-1, ncTb-2 and ncMTb-3) oligonucleotides. It also showed successfully discrimination between synthetic PCR analogues.

\section{References}

1. Arentz M and Hawn T R 2007 Drug Discov. Today Dis. Mech. 4231

2. Thiruppathiraja C, Kamatchiammal S, Adaikkappan P, Santhosh D J and Alagar M 2011 Anal. Biochem. 41773
3. Prabhakar N, Arora K, Arya S K, Solanki P R, Iwamoto M, Singh H and Malhotra B D 2008 Analyst 133 1587

4. Silva M M S, Cavalcanti I T, Barroso M F, Sales M G F and Dutra R F 2010 J. Chem. Sci. 122911

5. Chitravathi S, Swamy B E K, Mamatha G P and Sherigara B S 2011 J. Mol. Liq. 160193

6. Thomas T, Mascarenhas R J, Swamy B E, Martis P, Mekhalif Z and Sherigara B S 2013 Colloid. Surface B 110458

7. Donmez S, Arslan F and Arslan H 2015 Appl. Biochem. Biotech. 1761431

8. Zhang-yu Y U, Xiao-chun L I, Xue-liang W, Jinjin L and Ke-wei C A O 2011 Int. J. Electrochem. Sci. 63890

9. Gilbert O, Chandra U, Char M P, Swamy B E K, Char M P, Nagaraj C and Sherigard B S 2008 Int. J. Electrochem. Sci. 31186

10. Ma W and Sun D 2007 Acta Phys.-Chim. Sin. 23332

11. Chung D J, Kim K C and Choi S H 2011 Appl. Surf. Sci. 2579390

12. Hartati Y W, Topkaya S N, Maksum I P and Ozsoz M 2013 Adv. Anal. Chem. 320

13. Aladag N, Ozkan-Ariksoysal D, Gezen-Ak D, Yilmazer S and Ozsoz M 2010 Electroanal. 22590

14. Yu A M and Chen H Y 1997 Anal. Lett. 30599

15. Watterson J H, Piunno P A E, Wust C C and Krull U J 2000 Langmuir 164984

16. Li X M, Ju H Q, Du L P and Zhang S S 2007 J. Inorg. Biochem. 1011165

17. Bo Y, Wang W, Qi J and Huang S 2011 Analyst 136 1946

18. Abad-Valle P, Fernández-Abedul M T and Costa-García A 2007 Biosens. Bioelectron. 221642

19. Lucarelli F, Marrazza G, Palchetti I, Cesaretti S and Mascini M 2002 Anal. Chim. Acta 46993

20. Huang K-J, Niu D-J, Sun J-Y, Han C-H, Wu Z-W, Li Y-L and Xiong X-Q 2011 Colloids Surf., B 82543 